Motrivivência $\quad$ Ano XX, $\quad$ No 31, P. 274-292 $^{\circ}$ Dez./2008

\title{
O Currículo Básico Comum e a Formação Continuada: experiências com a Educação Física na Rede de Ensino Estadual/ES
}

\author{
Kezia Rodrigues Nunes' \\ Amarílio Ferreira Neto
}

\begin{abstract}
Resumo Abstract
O estudo analisa as práticas curriculares e acadêmicas da

Educação Física na Rede Estadual de Ensino do Espírito Santo, a partir de espaçostempos de Formação Continuada e problematiza essa produção, com base nos usos e apropriações dos praticantes escolares e nas narrativas, como intercâmbio de experiências. Discute as traduções feitas pelos professores sobre as teorizações da Educação Física no contexto de implementação de um Currículo Básico Comum nas escolas estaduais. Utiliza as produções individuais e coletivas
\end{abstract}

1 Mestre em Educação Física pelo PPGEF/UFES. Doutoranda em Educação pelo PPGE/UFES. Pesquisadora do PROTEORIA - Instituto de Pesquisa em Educação e em Educação Física. Contato: kezia@proteoria.org

2 Doutor em Educação. Professor do Programa de Pós-Graduação em Educação Física da UFES. Pesquisador do PROTEORIA. Contato: amarilio@proteoria.org 
dos professores para compreender a complexidade das relações, influências e contingências que permeiam suas práticas, para além do instituído ou previamente planejado.

Palavras-chave: Currículos; Metodologias; Formação Continuada. and contingencies that permeate their practices in addition to the previously established or planned.

Keywords: Curriculum; Methodologies; Continuing Formation.

\section{Introdução}

Sabia-se exatamente o significado da experiência: ela sempre fora comunicada aos jovens. De forma concisa, com a autoridade da velhice, em provérbios; de forma prolixa, com a sua loquacidade, em histórias; muitas vezes como narrativas de países longínquos, diante da lareira, contadas a pais e netos. Que foi feito de tudo isso? Quem encontra ainda pessoas que saibam contar histórias como elas devem ser contadas? Que moribundos dizem hoje palavras tão duráveis que possam ser transmitidas como um anel, de geração em geração? Quem é ajudado hoje por um provérbio oportuno? Quem tentará, sequer, lidar com a juventude invocando sua experiência? (BENJAMIN, 1994)
Contar histórias vivenciadas, trocar experiências profissionais, narrar possibilidades de trabaIho à luz de uma dentre as diversas propostas teórico-metodológicas da Educação Física. Existe espaço para essas demandas na universidade ou na escola? Essa problematização, ao modo de Benjamin (1994), a respeito da extinção da arte de narrar e de intercambiar experiências consistiu na estratégia teórico-metodológica no trabalho como professora formadora no Programa de Formação Continuada de Professores de Educação Física ${ }^{3}$ da Secretaria de Educação do Estado do Espírito Santo (SEDU), em dois encontros em 2009.

O programa compreendia o trabalho com onze Secretarias Regionais Estaduais (SREs), com turmas que envolviam entre $15 \mathrm{e}$ 45 professores de Educação Física.

3 As experiências desse texto são relativas ao primeiro módulo, intitulado: Educação Física Escolar: Abordagens e perspectivas no contexto atual. É preciso ressaltar que as atividades do programa foram interrompidas em 2010, por questões de ordem administrativa da Secretaria Estadual de Educação. 
Compunha o trabalho com cinco módulos temáticos, em encontros aos sábados, com 8h de duração. Entre atividades presenciais e nãopresenciais, previa-se $320 \mathrm{~h}$ de curso, entre os anos 2009 e 2010.

No trabalho com 25 professores/as na SRE do município de Cariacica, utilizamos suas narrativas como potência para compreender suas trajetórias de formação, suas experiências na Sedu, bem como para valorizar esse espaçotempo ${ }^{4}$ como possibilidade de construção de novas experiências coletivas. Assim, nossos encontros não se limitaram a formar, a dar forma às práticas dos/as professores/as, mas a perceber como diferentes saberesfazeres são tecidos e narrados por eles/as, o que nos leva a compreender esses momentos como de formação com os professores/as, e não formação de ou para os/as professores/as.

O tema central do Programa de Formação Continuada era o trabalho com o Currículo Básico Comum (CBC), documento construído entre 2004 e 2008 com a "[...] participação de cerca de 1.500 educadores, entre professores referência, consultores, professores convidados, pedagogos e representantes de movimentos sociais organizados" (CURRÍCULO BÁSICO COMUM, 2009, p. 12). $\mathrm{O}$ texto do documento anuncia-se como "[...] instrumento que visa a dar maior unidade ao atendimento educacional, fortalecendo a identidade da rede estadual de ensino, que se concretiza na práxis docente consonante com os princípios de valorização e afirmação da VIDA em todas as suas dimensões; mediante o resgate de princípios históricos construídos na área da educação, como a relação entre trabalho, ciência e cultura, tendo-se os estudantes na centralidade dos processos educativos" (p. 12).

$$
\text { O objetivo da Formação }
$$
era instrumentalizar os professores para o trabalho nas escolas estaduais, a partir do $\mathrm{CBC}$, a fim de garantir práticas que partissem da orientação desse documento. Embora o Programa de Formação Continuada previsse o estudo de textos acadêmicos que dessem visibilidade às propostas teóricometodológicas da Educação Físi$\mathrm{ca}$, de forma geral, e do CBC, de modo específico, optamos por um revés no conteúdo programático da proposta, em busca de conhecer primeiramente, pela narrativa dos/ as professores/as, o que tem sido

4 A estética de escrita que une termos consubstancia-se em uma crítica aos limites de compreensão da ciência moderna e de seu modo dicotômico de compreensão. Para além da oposição de termos, discutimos com Alves (2002) outras formas de pensar, analisar e ampliar a compreensão de seus significados, com novos modos de inventar e desestabilizar a escrita. 
produzido nas aulas de Educação Física em Cariacica/ES.

Com base na teorização de Certeau (1994) a respeito dos usos e apropriações, dos modos particulares de consumo, bem como dos estudos sobre a narrativa como intercâmbio de experiências (BENJAMIN; 1994) problematizamos o modo como a Educação Física tem sido praticada e produzida na escola, para além daquilo que é desejável institucionalmente, por meio de prescrições curriculares. Essa forma de análise perfaz ainda uma crítica à racionalidade moderna e ao modo particular de conceber o conhecimento, e suscita atenção a outros modos de perceber a vida, a escola e a Educação Física nesse contexto.

Este estudo justifica-se por buscar incorporar conhecimentos e significações dos professores da Rede Estadual de Ensino sobre as produções acadêmicas, curriculares e cotidianas, em busca de compreender a complexidade das relações, influências e contingências que permeiam suas práticas, para além do instituído ou previamente planejado. Ao mobilizar nossa sensibilidade para outras lógicas, para além das nossas, buscamos compreender outros discursos, que mesmo recorrentes nas escolas, possam parecer invisíveis ou inaudíveis ao debate acadêmico sobre ela, como nos su- gere os procedimentos sociológicos de Santos (2007).

Os dados foram produzidos com base no material utilizado para a avaliação do curso (atividades presenciais e não-presenciais), tais como: questionário, memorial, cartazes, ensaios, resumos e fotografias. Interessa-nos problematizar algumas questões: como esse documento é lido/discutido/utilizado nas escolas? Como garantir os modos particulares e criativos dos sujeitos tendo como base documentos ou teorias que buscam a padronização de opções e práticas?

\section{Redes de relações, saberes, fa- zeres e poderes na Formação Continuada}

Como o currículo é livre, hoje cada professor ensina o que quer, e o conteúdo acaba sendo determinado pelo livro didático. Agora será o currículo que vai determinar que livro será adotado, que tipo de laboratório a escola deve ter ou que tipo de formação o professor precisa receber (Adriana Sperandio, Secretaria Estadual de Educação, Jornal A Tribuna, 12/03/2009).

O CBC, construído na gestão 2004-2011 da Secretaria de Educação do Governo do Estado 
do Espírito Santo, é parte de um projeto de formação que envolve outros dispositivos para o regimento escolar. Dentre eles, podemos citar a construção de outros documentos balizadores, como: o Guia de intervenção pedagógica, o Regimento Comum, o Mais tempo na Escola e o Esporte na Escola. ${ }^{5}$

Embora a construção do CBC tenha envolvido diferentes atores do Sistema Estadual de Ensino, considerando os fazeressaberes construídos historicamente na SEDU, reconhecemos a distância existente entre as intenções e a complexidade da prática pedagógica cotidiana.

Certeau (1994) discute que os praticantes imprimem um fazer singular com relação às regras, produtos, leis e prescrições. Para além de consumidores do instituído, os sujeitos escolares constroem outras lógicas e regras com suas maneiras de fazer; ou seja, com estilos singulares de ação, para além da padronizada; que podem vir a originar novas maneiras de utilizar a ordem imposta.

Ao assumirmos a Formação Continuada com 25 professores de Educação Física, nossa expectativa consistia em conhecer as experiências construídas na Rede Estadual de Ensino, por professores com diferentes vivências, formações, práticas e tempos de trabalho. Sujeitos que vivem as práticas cotidianas e operam modos particulares de uso do que é instituído, de acordo com as necessidades reveladas nos contextos em que trabalham. Concordamos com a discussão de Oliveira (2008, p. 62-63):

Aceitamos as regras e, com elas atuamos, sempre. Por outro lado, sobre ela agimos, revertendo-lhes a lógica, criando espaços para aquilo que não está previsto, buscando, com isso, o desenvolvimento de nosso trabalho de acordo com nossas crenças e expressando valores não contemplados pelas regras oficiais, sejam elas comportamentais, práticas e/ou pedagógicas. Contamos essas histórias aos alunos, colegas e até superiores, e em outros relatos nos inspiramos para produzir nossos próprios e para agir. Nas histórias narradas e conhecidas, buscamos - e encontramos - inspiração para a nossa cotidiana luta pela liberdade de atuação e criação, para além das regras que nos amarram. É, também, no contato com essas histórias que aprendemos as possibilidades de astúcias, que construímos novos sentidos.

5 Disponível em <http://www.educacao.es.gov.br/>. 
Em busca de novos significados para a prática pedagógica da Educação Física que investigamos com os/as professores/as o que tem sido materializado no cotidiano das escolas da Rede Estadual em Cariacica/ES. Dentre os/as professores/as cursistas (13homens e 12 mulheres), todos trabalhavam com turmas de Ensino Médio e haviam participado em 2009 do Projeto Esporte Na Escola, critério exigido pela SEDU para a participação na Formação.

A apresentação da proposta do curso e a estratégia subsidiada pelas narrativas propiciaram uma breve explanação das experiências dos professores e das redes de relações que estabeleciam entre si. Percebemos a complexidade que envolve suas práticas, por exemplo, a partir da análise que eles realizam sobre o Projeto Esporte $\mathrm{Na}$ Escola, pelo Campeonato Estadual conhecido como Jogos Na Rede. A dissonância entre os sentidos desses jogos escolares foi expressa no debate em sala.

Para alguns professores, trata-se de um evento apreciado como um marco na história da Educação Física na Rede Estadual, por apresentar-se como estratégia de motivação para os alunos pelas diferentes experiências que a prática de esportes proporciona, tais como: treinamento esportivo, disciplina e trabalho em equipe, experiência com a organização de times e torcidas, bem como intercâmbio entre as escolas. A SEDU esta de parabéns com os jogos! Assim expressa o Professor P2.

Para outros professores, essa dinâmica apresenta-se contraditória com a proposta do $\mathrm{CBC}$, que busca a valorização de experiências para além da concorrência entre os alunos, mas, a partir desses jogos, têm dado evidência a um grupo restrito de estudantes bem como a uma disputa desigual, considerando as diferentes condições estruturais das instituições estaduais. É uma proposta incompatível com a referência teórica do $C B C$, discorda o Professor P22.

Outra interessante questão, problematizada por meio das narrativas e dos questionários, tratou-se dos critérios mais utilizados que motivam o delineamento dos conteúdos a serem trabalhados nas aulas de Educação Física desses professores, especialmente em 2009, ano em que o CBC chega às instituições educativas estaduais.

Dentre eles, $45 \%$ dos professores cursistas apontam como primordial atender às expectativas da comunidade escolar, especialmente a dos alunos. Assim, ao mesmo tempo em que revelam priorizar atividades culturais locais que atendam essa demanda, também 
optam pelo trabalho com atividades esportivas, em especial, voleibol, futsal e basquetebol. Outro fator determinante, que mobiliza $40 \%$ dos professores, é atender as orientações curriculares, tais como os Parâmetros Curriculares Nacionais (PCNs) do Ministério da Educação (MEC), o Currículo Básico Comum (CBC) da SEDU e as orientações sobre os Jogos Estaduais Escolares (Jogos Na Rede). Além disso, 15\% dos professores assumem que o trabalho é planejado tendo como consideração principal a estrutura física proporcionada (salas, pátios, quadras, terrenos próximos à escola) e o material pedagógico disponível para o trabalho (para além das bolas).

Embora parte desses professores tenha participado da construção do $C B C$, muitos admitem que outras demandas atravessam a ordem de prioridade nas instituições, e fazem com que o documento não seja tomado sempre como a priori, mas como mais uma referência para o trabalho. Ao analisar as narrativas dos professores, percebemos que os mesmos "[...] tecem suas práticas cotidianas a partir de redes, muitas vezes contraditórias de convicções e crenças, de possibilidades e limites, de regulação e emancipação. (ALVES, 2002, p. 96). Nesse emaranhado de saberesfazeres que buscamos organizar, reconhecemos que o instituído e o planejado sofrem tensionamentos de outras demandas cotidianas. Compreendemos que

Ao defendermos a centralidade das práticas, buscamos perceber o que não esta evidente, os discursos teóricos que estão presentes e subjazem às ações; entender, para além das aparências, as lógicas operatórias dos sujeitos envolvidos; decifrar o que ainda não foi dito. De certa forma, efetuar uma arqueologia das práticas (PÉREZ; AZEVEDO, 2008, p. 37).

Ao buscar um movimento complexo, para além da polaridade prática-teoria, o estudo do cenário da Educação Física escolar no século XX intencionava ampliar a visibilidade para questões políticas, econômicas, sociais e pedagógicas que influenciaram o movimento renovador da teorização da Educação Física escolar, a construção do $\mathrm{CBC}$ e as práticas pedagógicas na escola. Uma releitura das referências teórico-epistemológicas, das propostas, dos autores, das obras e das críticas foi fundamental para percebermos singularidades e rupturas da produção acadêmica bem como da proposta do CBC quanto à área de Educação Física. Especificamente sobre esse documento, transcreveremos as narrativas dos 
professores, discutidas em grupos, sobre suas impressões:

- A teoria predominante no CBC é a crítico-superadora, tendo como seu conteúdo os conhecimentos sobre o jogo, esporte, dança e ginástica. Sua finalidade é a transformação social, para isso usam a tematização da aula voltada para a cultura corporal. Busca levantar questões de poder, interesse e contestação, faz uma leitura dos dados da realidade à luz da crítica social dos conteúdos. Sendo assim, ela pode ser tida como uma reflexão pedagógica e desempenha um papel político-pedagógico, pois encaminha propostas de intervenção e possibilita reflexões sobre a realidade do homem (GRUPO 1).

- O texto do CBC esta baseado na concepção crítico-superadora, que tem como intuito superar alguns problemas políticos e sociais presentes no cotidiano escolar. A partir do diagnóstico, é feita uma leitura da realidade dos educandos, para que possam levar o aluno a reflexão, ação e transformação da realidade (GRUPO 3).

- Percebe-se no documento do $C B C$, a presença da abordagem crítico-superadora que é a opo- sição do mecanismo. Utiliza o discurso da justiça social como principal tendência. Suas raízes estão presentes no marxismo e no neo-marxismo. Essa abordagem define como objeto da Educação Física a cultura corporal em todas as suas possibilidades, levando o aluno a ter uma visão crítica do conteúdo apresentado. Apesar do CBC ter se definido por essa abordagem, percebemos também características de outras como saúde renovada, sistêmica e críticoemancipatória (GRUPO 2).

A respeito das continuidades e descontinuidades das propostas teórico-metodológicas de Educação Física, os professores tensionavam diferentes discussões, que envolviam suas experiências como alunos do Curso de Educação Física e como professores da Educação Básica, como na transcrição dos seguintes trechos:

- [...] algumas diferenças nas propostas só são esclarecidas com o tempo (Professora P10).

- Mas na Faculdade, quando terminei minha monografia sobre as propostas metodológicas e disse para a banca que me considerava um professor eclético, um dos professores disse que eu era muito confuso para ser 
considerado um bom professor (Professor P22).

- Mas depende de qual a sua proposta. Uma abordagem é mais específica para um tipo de trabalho. Quem está na escola sabe que não dá para trabalhar tudo com uma única teoria (Professora P5).

A crítica recebida pelo professor P22 é a mesma que Darido (2003, p. 23) faz às prescrições curriculares nacionais, como os PCNs (1994), o que não demonstra ser uma fragilidade expressa apenas na opção dos professores de Educação Física em formação inicial ou continuada, mas no âmbito das Secretarias de Educação Federal, Estadual e Municipal. A autora também adverte:

Apesar do grande número de abordagens no contexto da Educação Física escolar brasileira, é preciso ressaltar que a discussão e o surgimento destas tendências não significou o abandono de práticas vinculadas ao modelo esportivo, biológico ou, ainda, ao recreacionista, que podem ser considerados os mais freqüentes na prática do professor de Educação Física escolar.

É preciso considerar ainda os condicionantes que historicamen- te tensionam os desdobramentos da Educação Física na escola: a influência de concepções higienistas, escolanovistas, médicas, militares, esportivizantes, ginásticas e relacionadas com a saúde (DARIDO, 2003; VAGO, 2010). Não se trata, como afirma Vago (2010), de negar essas marcas, mas de perceber de que modo influenciam os programas de formação de professores e as práticas escolares. Também em evidenciar o potencial inventivo dos professores e alunos da escola básica para outras possibilidades criativas.
A história está aberta à perma- nente (re)construção de nossas experiências, então temos boas chances de (re)inventar manei- ras de fazer a Educação Física na escola, sempre 'com a saú- de', 'com a ginástica', 'com o esporte', e também 'com' a dança, os jogos, as brincadei- ras, a capoeira, e tantas outras práticas que são obras da cria- ção humana. Elas estão abertas à nossa inventividade (VAGO, 2010, p. 316).

Em nossos intercâmbios de experiências coletivas, percebemos uma tentativa dos professores em legitimar suas opções, ora com base nas propostas acadêmicas e curriculares, ora com base nas diferentes leituras possíveis do instituído no cotidiano escolar. As narrativas 
de suas experiências formadoras, consideradas ao modo de Certeau (1994) como táticas, como formas de enfrentamento de um modelo único para suas ações, possibilitam compreender novos usos e apropriações do que se busca hegemônico e homogêneo. Dar visibilidade às narrativas dos sujeitos cotidianos também revela outras proporções da pesquisa, como a "[...] possibilidade de fazer valer as dimensões de autoria, autonomia, legitimidade, beleza e pluralidade de estéticas dos discursospráticas dos sujeitos" (FERRAÇO, 2008, p. 32). Assim, também se faz importante ressaltar as possibilidades e os limites expressos pelos professores sobre o primeiro ano de implementação do $\mathrm{CBC}$ nas escolas estaduais:

- $\mathrm{O}$ documento serve como ponto de partida, como eixo-norteador para direcionar as aulas e os conteúdos a serem dados. Contudo, ainda não dispomos de material didático para as aulas de Educação Física e nem de um momento para discussão entre os professores de diferentes turnos da escola (GRUPO 1).

- Nota-se a necessidade de analisar o contexto social da escola e do seu entorno, a fim de avaliar possibilidades de mudança revendo a grade curricular, o envolvimento da comunidade e do corpo pedagógico da escola (GRUPO 3).

- A dimensão de possibilidades de conteúdos oferecidos a partir do $C B C$ é muito ampla. Levando-se em conta o número reduzido de aulas que se tem principalmente no Ensino Médio e na Educação de Jovens e Adultos, torna-se difícil o aproveitamento adequado no currículo do professor, já que o ENEM e outros exames também cobram questões referentes à área de Educação Física (GRUPO 2).

A análise dos professores nos espaçostempos em que trabaIham possibilita-nos compreender que o currículo do Ensino Médio é repleto de conteúdos e competências, que concorrem com demandas externas à escola e aos seus sujeitos. Cumprir prazos e projetos bem como preparar-se incessantemente para uma nova etapa (de educação ou trabalho) tem tomado parte substancial da organização dos temposespaços escolares. A inserção da Educação Física se insere com maior ou menor número de aulas no Ensino Fundamental e Médio, de acordo com o projeto da escola. É mais uma contradição percebida pelos professores a respeito das orientações da Secretaria de Educação com relação às peculiaridades das instituições do Estado. 


\section{O cotidiano escolar como possibilidade de outras lei- turas para o trabalho com Educação Física}

A narrativa tem sempre em si, às vezes de forma latente, uma dimensão utilitária. Essa utilidade pode consistir seja num ensinamento moral, seja numa sugestão prática, seja num provérbio ou numa norma de vida - de qualquer maneira, o narrador é um homem que sabe dar conselhos. Mas, se 'dar conselhos' parece hoje algo de antiquado, é porque as experiências estão deixando de ser comunicáveis. Em conseqüência, não podemos dar conselhos nem a nós mesmos nem aos outros [...] O conselho tecido na substancia viva da existência tem um nome: sabedoria. A arte de narrar está definhando porque a sabedoria - o lado épico da verdade - está em extinção (BENJAMIN, 2008).

Ensinamentos, conselhos, provérbios, histórias, receitas, memórias... as atividades coletivas e individuais possibilitavam que às teorias, fossem acrescentadas novas formas de compreender a Educação Física ao longo dos anos. Ao alternar atividades expositivas, individuais e em grupos, também evidenciávamos diferentes aspectos numa tessitura coletiva, com informações inesperadas para todos os professores. Contudo, o desafio de expressar e relatar nossas experiências foi interpretado como algo dificultoso por parte de muitos professores.

Benjamin (1994) trata dessa dificuldade ao focalizar a diminuição da atividade narrativa que, para o autor, é atravessada historicamente pelo progresso da ciência e da tecnologia. Dentre algumas influências sublinhadas por ele, destacamos: a arte do narrador baseia-se numa experiência coletiva, de memórias e trabalhos partilhados que passam de pessoa a pessoa (Erfahrung), que tem sido suprimida pela experiência vivida individualmente, que sofre intervenção apenas do conhecimento pessoal (Erlebnis); as narrativas pressupõem tempos próprios, orgânicos e artesanais, diferentes dos ritmos intensos impostos por uma sociedade industrial ou pós-industrial; ao contrário da informação, que se esgota em si mesma e só possui valor enquanto é novidade, a narrativa estabelece diálogos com os ouvintes e/ou leitores, permitindo produções variadas de sentidos e possibilidades, que sempre se renovam.

Com base na crítica que faz Benjamin do capitalismo, ques- 
tionamos uma concepção de modernidade que torna a experiência humana medíocre; que a transforma em vivência a reação a choques; que produz o declínio da faculdade de intercambiar experiências desse homem coisificado, o que acaba redundando no empobrecimento da sua humanidade e arriscando extinguir a própria arte de narrar (já que narração não é apenas produto da voz, mas de tudo o que foi aprendido na vida social) (NUNES, PEREIRA,1996, p. 15).

Para minimizar algumas dificuldades quanto ao receio de se expressar de forma oral ou escrita, alternamos atividades individuais e em grupos. Para a divisão dos grupos, não houve qualquer critério que pudessem trazer homogeneidade com relação aos períodos em que estudaram, às instituições em que se formaram, ao gênero, ou qualquer outro. Ao discutirmos sobre o memorial que produziram, onde expressam seus processos de escolarização bem como suas escolhas e oportunidades profissionais, pudemos identificar algumas mudanças na Educação Física no âmbito da educação básica.

Assim como Souza, Pinho e Galvão (2008, p. 82), compreendemos que "a utilização de narrativas biográficas em educação busca evidenciar e aprofundar representações sobre as experiências educativas e educacionais dos sujeitos, bem como potencializa entender diferentes mecanismos e processos históricos relativos à educação em seus diferentes tempos". Para Nunes e Pereira (1996, p. 53),

O desafio que se coloca para a escola é o de descobrir-se parte da vida, de buscar nessa vida o que dela foi negado, reinventar o sentido, desafio que se coloca também para a própria humanidade. É preciso não esquecer a astúcia, e, sobretudo, não perder o nome, não 'perder' o tempo, não perder a vida. Permitamo-nos buscar no passado aquilo que perdemos e que olhamos com melancolia, a fim de enriquecer nosso presente e, como diria Benjamin, torná-lo uma experiência contável.

Ao desafiarmos-nos a perfilar o tempo, recordar nossas experiências e construir outras coletivamente, buscamos compreender a complexidade das redes de saberes, fazeres e poderes que envolvem contextos escolares específicos, regionais e estaduais. Sem realçar a preponderância de um sobre o outro, como ensinam Pérez e Azevedo (2008), destacamos que se trata de um movimento entre lugares e espaços, entre estratégias e 
táticas, conforme aprendemos com Certeau (1994).

Linhales (2010) ainda nos alerta sobre não perdermos de vista as condições históricas que influenciam a produção das teorias metodológicas da Educação Física e as escolhas dos professores para o trabalho na escola. Assim, consideramos importante acrescentar às leituras acadêmicas outras histórias vividas individualmente e coletivamente pelos professores das escolas estaduais de Cariacica.

Aspectos estruturais foram destacados pelos professores do Grupo 1 e 4, a respeito das limitadas condições para as aulas de Educação Física nas escolas públicas em que estudaram, sem, no entanto, especificarem de que período estavam tratando. De acordo com suas narrativas, poucas instituições possuíam espaço físico adequado e não possibilitavam o acesso a material específico de cada modalidade esportiva. ${ }^{6}$ Também descrevem que as aulas eram obrigatórias, mas não eram ministradas por professores formados em Educação Física. A carência profissional foi suprimida pelo trabalho de voluntários, que mesmo não sendo professores de formação ou especialistas, gozavam de maior respeitabilidade perante os alunos e a comunidade. Os professores, assim, reforçam um discurso recorrente, um saudosismo referente a outras formas de se relacionar que parecem se perder com as mudanças que ocorrem em nossa sociedade.

Com relação à organização das aulas, os professores dos Grupos 1 e 2 relatam que estudaram em turmas dividas por gênero, que percebiam influência do militarismo na condução das aulas e no adestramento dos corpos. ${ }^{7}$ Contudo, na década de 1990, descrevem alterações metodológicas influenciadas pelo construtivismo. ${ }^{8}$

Com relação aos conteúdos, o Grupo 3 descreve que havia diferenciação por faixa etária. Assim, em suas experiências como alunos de $1^{\circ}$ a $4^{\circ}$ série do Ensino Fundamental, recorda-se da vivência de atividades como brincadeiras populares, brincadeiras de roda,

6 Problemas suficientemente detectados no processo de escolarização da Educação Física brasileira no Século XX. Quanto a esse debate, lançamos outras problematizações: que avaliação podemos fazer das demais disciplinas curriculares?

7 A respeito dessas questões, conferir estudos de Ferreira Neto, Maia e Bermond (2003).

8 Na história da Educação Física no Espírito Santo existem indícios de que essa concepção foi praticada de diferentes modos, de acordo com singulares formas de percebê-la e traduzi-la. 
piques, cantigas e recreação. ${ }^{9}$ Como alunos de $5^{\circ}$ a $8^{\circ}$ série, o trabalho foi modificado para atividades que envolviam danças, ginásticas, jogos pré-desportivos e desportivos e o trabalho com instrumentos musicais. No Ensino Médio, as atividades limitavam-se aos jogos desportivos e aos ensaios com a banda escolar.

Diante desses relatos, questionamos: essas experiências com relação a tempos, espaços, formas, conteúdos, modos, fazeres, saberes, poderes afetos e desejos influenciam nossas práticas como professores da educação básica? Compreendemos que a tessitura de nossas experiências profissionais sofrem diversas influências (escolares, familiares, acadêmicas, comunitárias) que extrapolavam o uso de uma abordagem teórico-metodológica específica. Dessa forma, "[...] tomar a narrativa como ponto de partida para apreender significações de episódios de ensino implica colocar o sujeito em contato com suas experiências, as quais são perspectivadas a partir daquilo que cada um viveu e vive, das simbolizações e subjetivações construídas ao longo da vida" (SOUZA, PINHO, GALVÃO, 2008, p. 82).

Na produção de um memorial a respeito de suas expe- riências com a Educação Física, como alunos da educação básica e superior, e como professores, percebemos como as situações cotidianas ultrapassam os planejamentos dos professores, dos acadêmicos, dos sistemas de ensino e da comunidade. O relato de uma professora, que também trabalha em outra região da Rede Estadual, demonstra uma prática pedagógica imbricada no contexto local, que potencializa outras dimensões de trabalho para a Educação Física na escola. Valemonos de duas de suas experiências para problematizar algumas dimensões vivenciadas.

- desde o ano 2008 que deixei de lado meu comodismo achando que por não ter espaço nem material adequado não poderia trabalhar o atletismo. Puro engano, estava negando Conhecimento aos meus alunos. Comecei com o ensino médio, com a finalidade de levá-los aos Jogos Na Rede. Pensei que não daria certo, que não teria motivação, que não seria capaz por achar que não dominava o conteúdo (ressalto que foi através de um minicurso de atletismo dado pela SEDU que obtive disposição e idéias para

9 Como exemplo das inúmeras publicações com características mais instrumentais que buscam orientar a prática pedagógica da Educação Física escolar, conferir a obra de Bosari, que influenciou gerações de professores na Educação Física brasileira. 
essa realização). Outro engano, pois o novo trouxe ânimo aos envolvidos. Introduzi as corridas, salto em distancia (a diretora mandou fazer uma caixa de areia perto do campo de futebol, mais ou menos $1 \mathrm{~km} \mathrm{da}$ escola, local de todos os treinamentos). Levei minha equipe aos jogos e foi surpreendente. Não tanto pela premiação (uma das minhas alunas conquistou medalha de outro nos 3000m), mas pela experiência que passamos. Este ano trabalhei com as $5^{a}$ e $6^{a}$ séries (corridas), utilizei o laboratório de informática para as pesquisas e apresentação dos trabalhos no PowerPoint, feitos em duplas. Depois usamos o espaço físico entorno da escola (ruas) para as aulas práticas de corridas $(100 \mathrm{~m}$ e $4 \times 100$ ). Por último foi realizado a culminância no campo de futebol, com todas as turmas de

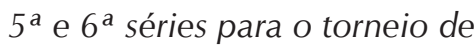
atletismo (PROFESSORA P21, TRECHO DO MEMORIAL).

Tratam-se de processos de subjetivação que buscam fixar o pertencimento à Rede Estadual de Educação, em valorizar os espaços de formação (como os cursos ministrados) bem como as orientações curriculares (que balizam e estimulam experiências com outras modalidades esportivas ainda não vivenciadas pelos sujeitos escolares). Em outros momentos de discussão, a professora $\mathrm{P} 21$ relata que em uma escola da Rede Estadual no município de Santa Leopoldina, um período de chuvas intensas no ano de 2009 provocou inundações no município e a perda de bens materiais e moradias de muitas famílias. Algumas crianças e adolescentes mostravam-se muito fragilizados com novas chuvas ou com quaisquer atividades que envolvessem água em abundância. Desviandose de uma orientação curricular estadual ou do cumprimento de um planejamento anual, buscou, com seus alunos/as, diferentes formas de brincar, jogar e vivenciar atividades nos rios da região. "Eu não esperava trabalhar com isso, mas foi uma necessidade encontrada por causa do trauma dos meus alunos", nos relata a docente.

Trata-se de uma professora que possui 26 anos de trabalho e que se mostrava, assim como muitos outros, sensível aos acontecimentos da escola. Ela fala de experiências gestadas por questões que moviam a escola na ordem do imprevisível, do inusitado, de uma demanda que a atravessou e mobilizou outras formas de pensar sua inserção como professora de Educação Física nesse contexto específico. Uma experiência ao modo de Larrosa (2002, p. 21). Para o autor, 
A experiência é o que nos passa, o que nos acontece, o que nos toca. Não que se passa, não o que acontece, ou o que toca. A cada dia se passam muitas coisas, porém, ao mesmo tempo, quase nada nos acontece. Dir-seia que tudo o que se passa está organizado para que nada nos aconteça. Walter Benjamin, em um texto célebre, já observava a pobreza de experiências que caracteriza o mundo. Nunca se passaram tantas coisas, mas a experiência é cada vez mais rara.

Contrariando algumas pesquisas que tratam da experiência profissional como distanciamento afetivo ou desinvestimento, ${ }^{10}$ os professores nos mostram, em suas narrativas, inovação e desejo de mudanças. Os relatos, ao modo de Certeau (1994), nos ajudam a enredar a complexidade de compreensões e vivencias sobre a escola. Para além dos prazos preestabelecidos, buscamos também evidenciar outras práticas, sensíveis às necessidades dos praticantes escolares.

\section{Outras questões}

[...] conteúdos básicos podem ser pensados como se houves- se uma categoria universal humana a ser defendida, um télos capaz de servir de base racional para as mais diversas decisões. Essa pretensão desconsidera a dimensão particularizada de todo universal - como diz Laclau (1996), o universal é sempre um particular que se hegemonizou -, como também retira o currículo da luta política sempre contingente. Todas as decisões sobre currículos são decisões contigentes, que exigem de nós conviver com o Outro, sem uma base racional para decidir como lidaremos com a diferença. Sem garantias. Mas é aí que nos colocamos em um processo democrático (LOPES, 2010, p. 35).

As problematizações propostas por Lopes (2010) sobre a permanente tensão entre o universal e o particular procuram ampliar concepções que se restringem a fundamentos universais, que fecham as significações das políticas. Consideramos essa discussão profícua para tratar também de outras referências que, para além de ampliarem possibilidades de trabalho, são lidas pelos professores como algo que engessa, que limita

10 Expressões tomadas da classificação de Huberman (1992), que estabelece fases para o ciclo de vida profissional docente: de 1 à 3 anos de carreira, a entrada; de 4 à 6 anos, a estabilização de um repertório profissional; de 7 à 25 anos, conservadorismo; de 25 à 40 anos, o desinvestimento. 
que não potencializa a expansão do pensamento, das práticas, do trabalho, do conhecimento, dos relacionamentos, da vida.

Ao buscar evidenciar a tensão vivenciada no cotidiano de algumas escolas estaduais por meio das narrativas de um grupo de professores de Educação Física, nos afastamos das análises que consideram conteúdos mínimos ou teorizações acadêmicas como únicos, almejados e corretos, em que a complexidade e peculiaridade dos contextos escolares é concebida como acessório a ser incluído. O inverso também mostra-se pertinente, de forma que seria ingênuo conceber instituições e sujeitos descolados dessas influências e determinações. É pela tensão e pelo movimento complexo das redes de relações que nos interessamos.

Nas experiências relatadas nesse trabalho, discutimos que as narrativas dos docentes elucidam sempre outras questões, evidenciam diferentes problematizações e nos convidam a novas experimentações. Assim como em outra experiência de formação em Educação Física (BERTO; NUNES, 2010), o enredamento dessas narrativas não tem a pretensão de traduzir representações sobre a escola, mas de falar no/sobre/com um espaçotempo destinado a trocar experiências e construir outras co- letivamente num exercício de intercâmbio. Contudo, outras questões ainda pulsam quando tratamos das peculiaridades de nossas práticas pedagógicas: porque os alunos e suas famílias são pouco interrogados sobre o que necessitam experienciar, sobre/com o que lhes move nas aulas de Educação Física?

Consideramos a relevância em se discutir propostas teóricometodológicas da Educação Física, mas também salientamos a importância em manter atenção ao que tem sido produzido nas escolas. Assim como sugerem Soares et all. (2010, p. 12-13), também "[...] consideramos a necessidade de pensar esse componente curricular de modo integrado às problemáticas da escola como um todo. Essa integração é precípua para a reflexão das possibilidades da EF da escola e também para a própria qualidade do ensino". Pensar na Educação Física como experiência para a vida dos sujeitos escolares, para além do que pode ser pensado apenas na escola. Um desafio que os professores das escolas básicas também tem se dedicado a planejarpraticarteorizar.

\section{Referências}
ALVES, Nilda et al. Criar currículo no cotidiano. São Paulo: Cortez, 2002.


BENJAMIN, Walter. Magia e técnica, arte e política: ensaios sobre literatura e história da cultura. São Paulo: Editora Brasiliense, 1994. (Obras escolhidas V. 1).

BERTO, Rosianny C.; NUNES, Kezia R. Narrando experiências e constituindo espaços de intercâmbio na formação de professores de educação física da educação infantil. In:ENCONTRO NACIONAL DE DIDÁTICA E PRÁTICA DE ENSINO, 15., 2010, Belo Horizonte. Anais... Belo Horizonte: UFMG, 2009. 1 CD-ROM.

BOSARI, José Roberto (Org.). Educação física da pré-escola à universidade. São Paulo: Editora Pedagógica e Universitária, 1980.

CERTEAU, Michel de. A invenção do cotidiano: 1. Artes de fazer. Petrópolis: Vozes, 1994.

DARIDO, Suraya Cristina. O contexto da educação física escolar. In: . Educação física na escola: questões e reflexões. Rio de Janeiro: Guanabara Koogan, 2003. p. $1-24$.

ESPÍRITO SANTO (ESTADO). Secretaria da Educação. Currículo Básico Escola Estadual. Ensino médio: área de Linguagens e Códigos. Secretaria da Educação. Vitória: SEDU, 2009.

FERREIRA NETO, Amarílio; MAIA,
Ediane Melo; BERMOND, Magda Terezinha. Revista de Educação Física: ciclo de vida, seção unidade de doutrina e lição de educação física (19322002). Revista Movimento, Porto Alegre, v. 9, n. 1, p. 91118, 2003.

FERRAÇO, Carlos Eduardo. A pesquisa em Educação no/do/ com o Cotidiano das Escolas. In: FERRAÇO, Carlos Eduardo, PEREZ, Carmem Lúcia Vidal, OLIVEIRA, Inês Barbosa (Org.). Aprendizagens cotidianas com a pesquisa: novas reflexões em pesquisas nos/dos/com os cotidianos das escolas. Petrópolis: DP et Alli, 2008. p. 23-34.

LARROSA, Jorge. Notas sobre a experiência e o saber da experiência. Revista Brasileira de Educação. N. 19, jan/fev/mar/ abr., 2002. p. 20-28.

LINHALES, Meily Assbú. Sobre educação, corpo e história: fragmentos de práticas. In: SANTOS, Lucíola L. de C. et al. (Org.). Convergências e tensões no campo da formação e do trabalho docente. Belo Horizonte: Autêntica, 2010. p. 271-283.

LOPES, Alice Casimiro. Currículo, política e cultura. In: SANTOS, Lucíola L. de C. et al. (Org.). Convergências e tensões no campo da formação e do trabalho 
docente. Belo Horizonte: Autêntica, 2010. p. 23-38.

NUNES, Maria Fernanda Rezende; PEREIRA, Rita Marisa Ribes. Buscando o mito nas malhas da razão: uma conversa sobre educação e teoria crítica. In: KRAMER, Sônia; JOBIM E SOUZA, Solange (Org.). Histórias de professores: leitura, escrita e pesquisa em educação. São Paulo: Ática, 1996. p. 43-54.

OLIVEIRA, Inês Barbosa de. Certeau e as artes de fazer: as noções de uso, tática e trajetória na pesquisa em educação. ALVES, Nilda; OLIVEIRA, Inês Barbosa de (Org.). Pesquisa nos/dos/com os cotidianos das escolas: sobre redes de saberes. Petrópolis: DP et Alii, 2008. p.

SANTOS, Boaventura de Sousa. Renovar a teoria crítica e reinventar a emancipação social. São Paulo. Boitempo, 2007.

SOARES, Antônio Jorge et al. A pedagogia esportivizante da educação física no contexto da escola eficaz. In: ENCONTRO NACIONAL DE DIDÁTICA E PRÁTICA DE ENSINO, 15., 2010, Belo Horizonte. Anais... Belo Horizonte: UFMG, 2009. 1 CD-ROM.

VAGO, Tarcísio Mauro. Educação física e a cultura escolar: notas de reflexão. In: SANTOS, Lucíola L. de C. et al. (Org.). Convergências e tensões no campo da formação e do trabalho docente. Belo Horizonte: Autêntica, 2010. p. 311-324.

Recebido: 11/fevereiro/2010. Aprovado: 22/abril/2010. 